\title{
Analysis of Blended Learning Model Application Using Text Mining Method
}

\author{
https://doi.org/10.3991/ijet.v16i01.19823
}

\author{
Lin Wang ${ }^{(凶)}$, Yanfen Huang, Muhd Khaizer Omar \\ Universiti Putra Malaysia, Serdang, Malaysia \\ 2010020009 ezqu. edu.cn
}

\begin{abstract}
The rapid development of networks has resulted in the recognition of blended learning as an effective learning model. The text mining method was used to analyze the blended learning practice data of 17 countries provided by the Christensen Institute. By classifying and extracting text information from the use of blended learning model selection and the challenges of blended learning, the factors that hinder the implementation of blended learning were analyzed. The distribution of blended learning courses and practice models in each country were discussed, as was the influence relationship between the region and implementation model. The results demonstrate that the practice of blended learning in primary and secondary schools is mature in four courses of English, Mathematics, Science, and Social Research. The blended learning implementation model can be unaffected by the region, but more tend to "mix." The practice cycle of blended learning becomes long and requires long-term stable support, while teachers' ability and students' ability preparation are the largest obstacles to the effectual development of blended learning. This study provides references for improving the efficiency of blended learning practices, especially in the aspects of practice model selection, infrastructure preparation, and teacher and student ability training.
\end{abstract}

Keywords—Blended learning, online teaching, text mining, education, virtual learning

\section{Introduction}

The development of educational informatization and information communication technology has promoted the emergence of an innovative subversive educational model named blended learning. Massive-scale learning platforms, such as Udemy, Coursera, Open Culture, and edX, accelerate the development of blended learning models that combine face-to-face learning with other typical functions in online learning. This acceleration has likewise become an established trend in the development of teaching models in higher education in the future [1]. Theoretical studies on blended learning have spanned 20 years, but the concept of blended learning remains inconclusive. Scholars, such as Zhu Zhiting [2], Yu Shengquan [3], and Feng Xiaoying [4], all defined blended learning from their own perspectives. 
Therefore, inaccuracy hinders the further exploration of the practical value and significance of blended learning. From the current development of the blended learning model, the implementation strategies of the model remain in the exploratory stage [5]. Numerous studies focus on the challenges brought by the implementation of this teaching method, and differences arise between practice development and identity of blended learning. For example, Banyen (2016) proved that Thai university students were very satisfied with the effect of blended learning [6]. Blended learning in China has been proven helpful in solving authentic problems in colleges and vocational education and has played a positive role in students' practical training and students' learning satisfaction has been greatly improved [7-9]. However, the application effect in primary and secondary education is not obvious. For example, technology is used only on the surface of education and teaching, and the substantive problems have not been effectively solved [10]. Thus, K-12 schools that carry out blended learning often seek technical support and build their practice modes by relying on their individual learning platforms. The practical results often show a customized state. This blended learning model increases the time of practical exploration. Effective reference and knowledge sharing among peers are lacking in aspects such as school management, resource preparation, and teacher training, considerably reducing the effectiveness of blended learning implementation. These obstacles bring great challenges to the study and promotion of blended learning. Therefore, analysing the distribution of the blended learning curriculum, the distribution of implementation modes, and the relationship between regions and implementation modes is an urgent problem.

On the basis of the above analysis, this study conducts an in-depth analysis of the present situation of blended learning practice in the primary and secondary education stages. Exploring the problems in the practice of multiple blended learning models and identifying the obstacles that affect its development are important to guide the effective selection of blended learning models, as is the correct implementation of strategies in the design and development of teaching activities.

\section{State of Art}

Scholars have attempted to give blended learning a clear and widely accepted definition after practical studies. In 2001, Harvi and Chris [11] wrote that "Blended learning focuses on optimizing the achievement of learning objectives by applying the 'right' learning technologies to match the 'right' personal learning style to transfer the 'right' skills to the 'right' person at the 'right' time." In this definition, no emphasis has been placed on the use of eLearning and online education platforms but rather on the appropriate application of multiple technologies in education. This definition has blurred the perception of blended learning. At present, scholars think that as long as technology is used in the teaching process, blended learning occurs. In 2003, He [12] proposed that "so-called blended learning combined the advantaged of traditional learning methods with that of e Learning."

Curtis (2007) [13] defined blended learning as "the combination of face-to-face teaching and online learning." In 2009, when interviewed by Zhan Zehui and Li 
Xiaohua of South China Normal University, Curtis again elaborated on the difference between blended, flexible, and hybrid learning. Scholars agreed that blended learning was characterized by fusion rather than the flexible application of various technologies in traditional classrooms [14]. According to Li Fengqing (2016), the definition of blended learning concept was discussed from four aspects: mastering learning theory, primary teaching principle, deep learning theory, and active learning theory [15]. However, many teachers still did not have a way to determine whether their practice was a blending learning model. For example, in certain articles [16-17], the themes were blended learning, but the specific study content tended to use learning platforms such as Claroline and Superstar Learning in the course. Strictly speaking, this approach was not blended learning and could only be called "technology-rich." In 2015, Horn and Staker [18] argued that blended learning was any time a student learns at least in part at a supervised brick-and-mortar location away from home and at least in part through online delivery with some element of student control over time, place, path, and/or pace. This idea is compared with the concept posited by He (2004), which is recognized by Chinese scholars.

Although these two concepts are separated by a large time span, they have common features:

- The blended learning method must include eLearning and the ability to conduct online learning.

- The content of the learning is not arbitrarily selected but must be formal learning and can be combined with traditional teaching methods.

- The role of supervision is emphasized.

Professor He's position on supervision emphasized that teachers should monitor the teaching process. Horne and Staker emphasized that students' learning places should have supervisors, and the supervisors could be teachers or instructors. These two concepts have two differences:

- Different ideas of physical places. In China, the physical place generally refers to the school, and the classroom is typically a fixed classroom. The physical place mentioned in Horne and Staker's concept generally refers to all places except the family home, as long as teachers or instructors are available to supervise. For instance, learning centres and computer rooms in shopping malls can become physical places for blended learning.

- Different ideas about student autonomy. For Professor He, students must have the ability to learn autonomously, and the curriculum design should be able to stimulate students' learning initiative and creativity. By contrast, Horne and Staker emphasize the individualization of students' learning, the individualization of their learning paths, and the integrated learning experience.

From the concepts, different scholars understand the concept of blended learning differently, inevitably affecting the establishment of blended learning models, including the design and development of blended learning practices and the evaluation of practical results. Eventually, unclear definition of blended learning will 
affect people's judgment about the effect of blended learning. Correctly predicting the future direction of blended learning is impossible. Therefore, the study analyses the implementation of blended learning practices in different countries, compares the implementation models, platforms, and practical courses adopted and clarifies the root causes of the difficult problems in blended learning practice to increase the effectiveness of blended learning implementation in the future.

The remainder of this study is organized as follows. Section 3 describes the practice model of blended learning and the analysis model of practice data. Section 4 analyses the distribution of implementation model and course selection. By using the logistics regression model, the relationship between the implementation model and the region is obtained, and the word frequency analysis of open problems is carried out by using text mining technology. Section 5 summarizes the conclusions.

\section{$3 \quad$ Methodology}

\subsection{Blended learning implementation model}

Blended learning models in the primary and secondary education stages in the United States and other countries were mainly divided into four categories [19]: Rotation, flex, a la carte, and enriched virtual.

The first type is the rotation model, which is familiar to educators. Teachers designed different learning modules in a course, and students can take part in the study of each module according to the teacher's arrangement and fixed schedule. In these modules, one module must be guaranteed to be learned online (Figure 1).

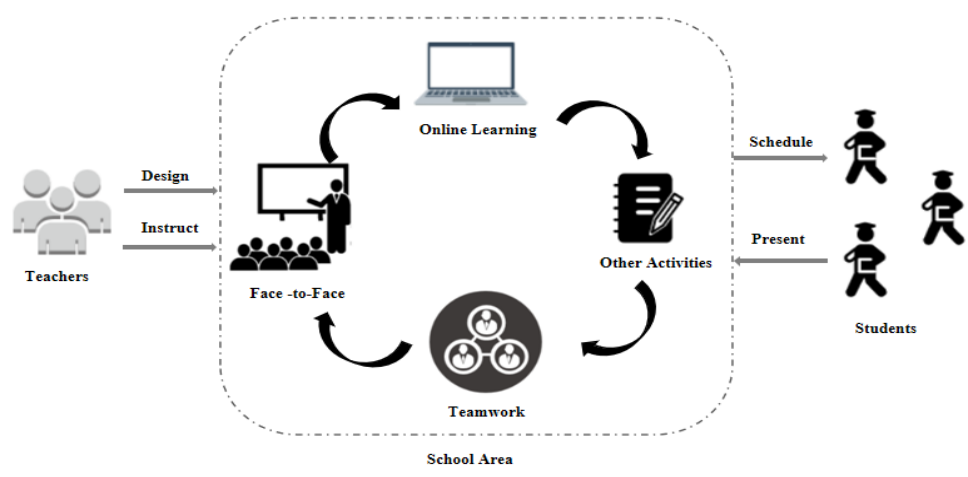

Fig. 1. Rotation model

The second type is the flex model, which is a flexible learning model in blended learning that mainly comprises online learning. Although the flexible learning model used online learning, all learning activities were mainly completed in school. The typical characteristic of this model was emphasizing the students' individualized 
learning styles because students can arrange their learning activities freely according to the flexible schedule of learning modules. Teachers can also have additional time for on-site tutoring. Therefore, the flex model had three characteristics that were it can adjust students' learning style independently, increase teaching resources flexibly, and combine teachers' teams flexibly (Figure 2)

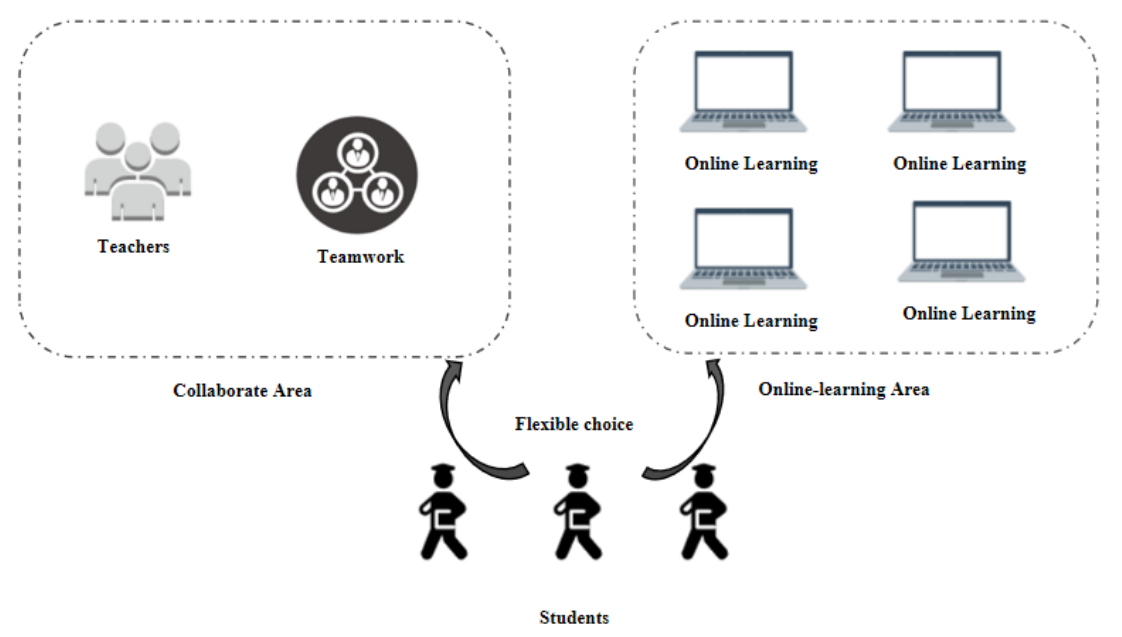

Fig. 2. Flex model

The third type is the a la carte model, the appearance of which is considerably affected by the school's own conditions, as elaborated on in Section 4. In this model, the school's curriculum resources often cannot fully meet the learning needs of students, so one of the courses or subjects needs to be learned online. Therefore, online activities in this learning style might not necessarily require completion in school but students also attended other face-to-face courses in the school. The characteristics of the model were summarized as follows: (a) the course was a complete online course; (b) students' learning location was not restricted, and (c) the teacher was the online teacher in the online learning platform (Figure 3).

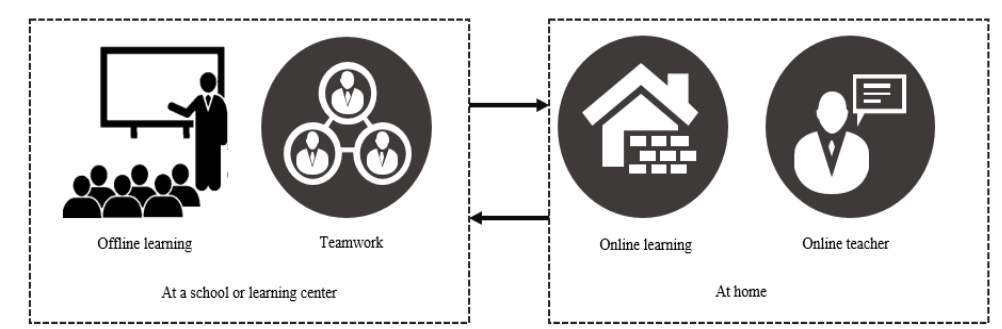

Fig. 3. A la carte model 
The last type is the enriched virtual model, which originated in full-time online learning schools. Given that this type of school cannot meet the students' learning needs; it promoted the emergence of offline physical schools or learning places (Figure 4).

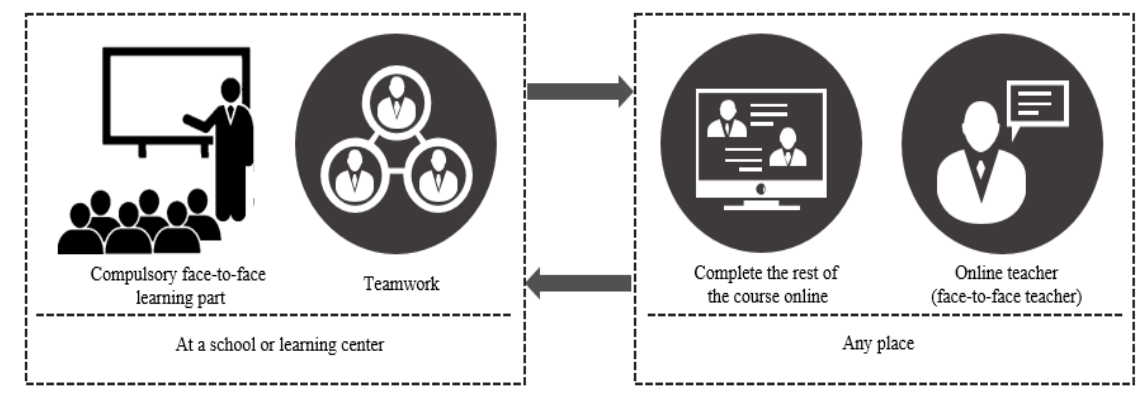

Fig. 4. Enriched virtual model

Typical characteristics were as follows.

- First, students can complete online courses independently, but must also complete the school's offline course content.

- Second, teachers were online and offline course instructors.

- Third, the school's learning and communication activities were fixed.

\subsection{Text mining technology}

Text mining belongs to the application field of natural language processing technology. In qualitative study, the text mining method can be used to analyse the materials used and collected in the study. These materials included case studies, personal experience, life stories, interviews, observations, history, interactions, and visual texts that described routine and problematic moments and meanings in an individual's life [20]. In the study process, qualitative study tended to ask about the nature of the phenomenon or how the complex process worked and was perceived or how meaning was constructed [21]. Therefore, qualitative study itself is an iterative process [22]. With the help of text mining technology, this study can realize a deep understanding of factors such as the teaching model used in each school, the technology adopted, and prominent challenges.

The data used in this study came from the Blended Learning Universe Directory Data 2016-2019 developed by the Clayton Christensen Institute in the United States. The directory summarized the basic data of 675 schools in 17 countries from January 1, 2011 to July 23, 2019 and the implementation of blended learning practices. The number of students participating was 150,000 . The questionnaire was a non-scale questionnaire that comprised 162 options that could be divided into five categories, namely, blended learning profile, school information, course platform, selected courses, and four open questions. 
1) Frequency analysis model: Based on the analysis of the sample background and basic status, the frequency distribution of the corresponding variables in the questionnaire was detected by using the frequency analysis and multiple response analysis in Statistical Product and Service Solutions (SPSS). Frequency distribution was formed after grouping the category variables. The formula was

$$
f_{n}(A)=\frac{n_{A}}{n}, 0 \leq f_{n}(A) \leq 1
$$

Based on this model, the study analysed the distribution of blended learning curriculum, blended learning implementation model, and practice school type.

2) Logistic regression model: Given that countries (country), implementation modes (implementation_type) and regions (city_type), as dependent variables of this questionnaire, all belonged to more than three types of disordered classification variables, the data analysis model adopted the disordered multi-classification logistic regression model. The formula was

$$
\ln \frac{p}{1-p}=\beta_{0}+\beta_{1} x_{1}+L+\beta_{k} x_{k}
$$

3) Text information mining: Bryman (2004) proposed that qualitative analysis could include discourse analysis, conversation analysis, texts and documents analysis [23]. The text analysis method analysed, recognized, and classified the text itself, so that the indirectness, potential motivation, and effect of the text could be mined [24]. This questionnaire includes four open questions, namely, "When did you first implement blended learning?", "Why did you choose that particular model?", "What was one of your biggest challenges when moving to blended?", and "How did you overcome it?". A total of 600 schools answered and provided feedback on the questions according to their blended learning practice. Therefore, in the analysis, the original corpus was processed into the same format, and the highfrequency words in the document were counted. Then, the related word frequency analysis was performed between the high frequency words and the classification to explore the problems in the process of blended learning practice.

\section{$4 \quad$ Result Analysis and Discussion}

\subsection{Demographic results}

Of the 675 blended learning practice projects participating in the survey, 600 were in the United States, accounting for $74 \%$ of the total. A total of 43 were from developing countries, accounting for $6 \%$. Among the participating schools, only two schools had blended learning programs for adults, and 163 were for kindergarteners, with 162 from the United States and only 1 from South Africa. In other words, 75.6\% of the blended learning practice projects carried out was implemented at the $\mathrm{K}-12$ 
stage: 332 schools conducting blended learning are located in cities, 237 are located in suburban areas, and only 66 are in rural areas, comprising 2 in Malaysia, 1 in South Africa, and 63 in the United States. A total of 345 public schools participated in blended learning, accounting for $51 \%$ of the total, and Table 1 shows that eight countries implemented blending learning in private schools. Thus, when schools investigated the recommendations for developing blended learning practices, certain schools proposed giving the blended learning models a new label to attract students to join. The total number of courses using blended learning was 61 , of which 541 schools chose mathematics courses, 484 chose English courses, 358 chose science courses, and 337 chose social studies courses. Science courses and social studies courses using blended learning are mainly conducted in the United States. Therefore, the practical experience of online mathematics and English classes is more mature than that of other courses.

Table 1. Statistics of blended learning course distribution

\begin{tabular}{|c|c|c|c|c|}
\hline & & \multicolumn{2}{|c|}{ Responses } & \multirow[b]{2}{*}{ Percent of Cases } \\
\hline & & $N$ & Percent & \\
\hline \multirow{7}{*}{ Subjects } & English_language_arts & 484 & $25.5 \%$ & $81.3 \%$ \\
\hline & Social_studies & 337 & $17.8 \%$ & $56.6 \%$ \\
\hline & Computerprogramming & 77 & $4.1 \%$ & $12.9 \%$ \\
\hline & Math & 541 & $28.5 \%$ & $90.9 \%$ \\
\hline & Science & 358 & $18.9 \%$ & $60.2 \%$ \\
\hline & \begin{tabular}{|l}
$\ldots \ldots$ \\
\end{tabular} & $\ldots \ldots$ & $\ldots \ldots$ & $\ldots \ldots$ \\
\hline & Robotics & 1 & $0.1 \%$ & $0.2 \%$ \\
\hline \multicolumn{2}{|l|}{ Total } & 1896 & $100.0 \%$ & $318.7 \%$ \\
\hline
\end{tabular}

(Source : https://www.blendedlearning.org/research/)

\subsection{Application analysis of the blended learning model}

The blended learning models in the primary and secondary education stages in the United States and other countries are mainly divided into four categories: Rotation, flex, a la carte, and enriched virtual. This mixed learning practice as a whole, as shown in Table 2, indicates that the sustaining model (Station Rotation, Lab Rotation, Flipped Classroom, and Individual Rotation) and the disruptive model (Individual Rotation, Flex, A La Carte, and Enriched Virtual) account for the same proportion. However, the difference analysis of the blended learning model selected by the United States and other countries, as shown in Table 3 , is $\mathrm{p}<0.05$, indicating a significant difference. The main reason for this result is that the enriched virtual model in the disruptive model is exclusively used in the United States, involving 33 schools. Overall, the blended learning model in the primary and secondary education stage is inclined to choose the continuation model to practice, and an increasing number of begin to tend to "mix." A variety of blended learning models are mixed for practice, accounting for $22 \%$, second only to the conversion model, meaning that the development of blended learning models is not limited to the only form. 
Through the logistic regression analysis of the implementation area of blended learning, as shown in Table 3 , the record is $p=0.202>0.05$. This result means that no significant difference is found between the regions of this test. This finding shows that, overall, the blended learning implementation model will not be affected by the region when it is selected. However, the a la carte model is an exception. In terms of the relationship between school area and the blended learning model (Table 4), the selected a la carte model is mostly concentrated in the rural and the suburbs. The percentage of urban city which choose a la carte mode is only $1.6 \%$.

Table 2. Statistics of the distribution of blended learning models

\begin{tabular}{|c|c|c|c|c|c|}
\hline & & Frequency & Percent & Valid Percent & Cumulative Percent \\
\hline \multirow{7}{*}{ Valid } & Rotation & 262 & 38.8 & 42.1 & 42.1 \\
\hline & A la carte & 34 & 5.0 & 5.5 & 47.5 \\
\hline & Mix & 153 & 22.7 & 24.6 & 72.1 \\
\hline & Flex & 101 & 15.0 & 16.2 & 88.3 \\
\hline & Enriched Virtual & 33 & 4.9 & 5.3 & 93.6 \\
\hline & \begin{tabular}{|l|} 
Individual Rotation \\
\end{tabular} & 40 & 5.9 & 6.4 & 100.0 \\
\hline & Total & 623 & 92.3 & 100.0 & \\
\hline Missing & System & 52 & 7.7 & & \\
\hline & Total & 675 & 100.0 & & \\
\hline
\end{tabular}

(Source: https://www.blendedlearning.org/research/)

Table 3. Test on the differences of blended learning model selection in the United States and other countries

\begin{tabular}{|l|l|c|c|c|c|c|c|c|}
\hline \multicolumn{2}{|c|}{} & \multicolumn{2}{|c|}{$\begin{array}{c}\text { Levene's Test for } \\
\text { Equality of Variances }\end{array}$} & \multicolumn{5}{c|}{ t-test for Equality of Means } \\
\cline { 2 - 8 } \multicolumn{2}{|c|}{} & $\boldsymbol{F}$ & Sig. & $\boldsymbol{t}$ & $\boldsymbol{d f}$ & $\begin{array}{c}\text { Sig. } \\
(2-\text { tailed) }\end{array}$ & $\begin{array}{c}\text { Mean } \\
\text { Difference }\end{array}$ & $\begin{array}{c}\text { Std. Error } \\
\text { Difference }\end{array}$ \\
\hline \multirow{2}{*}{$\begin{array}{l}\text { Type } \\
\text { sum }\end{array}$} & $\begin{array}{l}\text { Equal variances } \\
\text { assumed }\end{array}$ & 10.578 & .012 & 2.406 & 8 & .043 & 107.000 & 44.471 \\
\cline { 2 - 9 } & $\begin{array}{l}\text { Equal variances not } \\
\text { assumed }\end{array}$ & & & 2.406 & 4.213 & .071 & 107.000 & 44.471 \\
\hline
\end{tabular}

(Source: https://www.blendedlearning.org/research/)

In other words, blended learning tends to be dynamic in the process of development. Each model seeks complementarity, and the strategy of practical development becomes increasingly flexible. Overall, the regional influence is not significant. 
Table 4. Relationship between the school area and the blended learning models

\begin{tabular}{|c|c|c|c|c|c|c|c|c|}
\hline & \multicolumn{5}{|c|}{ Blended_learning_type } & \multirow[b]{2}{*}{ Total } \\
\hline & & & Rotation & $\begin{array}{l}\text { A Lar } \\
\text { Charte }\end{array}$ & Mix & Flex & $\begin{array}{c}\text { Enriched } \\
\text { Virtual }\end{array}$ & \\
\hline \multirow{8}{*}{$\begin{array}{l}\text { school_} \\
\text { community_type }\end{array}$} & \multirow{2}{*}{ urban } & Count & 143 & 10 & 83 & 56 & 17 & 309 \\
\hline & & $\%$ of Total & $23.0 \%$ & $1.6 \%$ & $13.3 \%$ & $9.0 \%$ & $2.7 \%$ & $49.6 \%$ \\
\hline & \multirow{2}{*}{ suburban } & Count & 78 & 19 & 55 & 52 & 12 & 216 \\
\hline & & $\%$ of Total & $12.5 \%$ & $3.0 \%$ & $8.8 \%$ & $8.3 \%$ & $1.9 \%$ & $34.7 \%$ \\
\hline & \multirow{2}{*}{ rural } & Count & 28 & 6 & 14 & 12 & 2 & 62 \\
\hline & & $\%$ of Total & $4.5 \%$ & $1.0 \%$ & $2.2 \%$ & $1.9 \%$ & $0.3 \%$ & $10.0 \%$ \\
\hline & \multirow{2}{*}{ others } & Count & 11 & 3 & 12 & 7 & 3 & 36 \\
\hline & & $\%$ of Total & $1.8 \%$ & $0.5 \%$ & $1.9 \%$ & $1.1 \%$ & $0.5 \%$ & $5.8 \%$ \\
\hline \multirow{2}{*}{\multicolumn{2}{|c|}{ Total }} & Count & 260 & 38 & 164 & 127 & 34 & 623 \\
\hline & & $\%$ of Total & $41.7 \%$ & $6.1 \%$ & $26.3 \%$ & $20.4 \%$ & $5.5 \%$ & $100.0 \%$ \\
\hline
\end{tabular}

(Source: https://www.blendedlearning.org/research/)

\subsection{Analysis of the reasons for selecting a blended learning model}

As countries develop, they gradually increase their education. Therefore, educators continue to explore a variety of education models to achieve the transformation of education from a quantitative to a qualitative style of learning [25]. Although this transition means educators hope to gradually help students improve their learning output (learning effect) with the increase of learning input (education model), they also hope that as learning input increases, a qualitative style of learning will occur. These activities ultimately lead to radical and significant changes in the quantity or nature of cognition or behaviours or both. By analysing the answer to Question 161 ("Why choose a blended learning model?"), the study found the following reasons for schools to select a sustainable blended learning model.

Significant results achieved on a small scale. Many schools have organized a team of specialized teachers to try a class or a course before launching a blended learning model. The success of the small-scale experiment inspires the confidence of the whole school to carry out blended learning practice. Importantly, the success provides other teachers with a template for blended learning that can be referenced at close range.

Funding from international blended learning organizations. The funding of the international blended learning organization includes two activities. First, a school actively contacts an international blended learning research organization, such as the Lemann Foundation, to obtain their assistance with hardware resources or funds. Second, all of a school's teachers use their vacation to collectively participate in the online blended learning model. Many schools have mentioned in their feedback that teachers' participation in information and communication technology training has not been able to meet the needs of blended learning models. Thus, teachers need to learn more targeted blended learning models and have hands-on experience.

Feedback from college graduates. Colleges and universities have pioneered online learning, allowing many college students to be exposed to the blended learning model. They have first-hand experience. They are also experienced in using online learning 
platforms. For example, a teacher at SK Convent Sentul School in Malaysia used the platform Frog VLE when she was studying at university, so she actively used this platform to develop a small-scale blended learning model in her class after she became a teacher. Two years later, the VLE platform was promoted throughout the school, prompting the development of a blended learning model throughout the school.

Significant effects on students' long-term learning ability. Escola Projeto School in Brazil, SMK Methodist School in Malaysia, Future Nation Schools, and High-Tech High in the United States found that the practice of blended learning enabled students to learn more consciously and confidently, helping them become capable learners. This autonomous learning ability will become increasingly prominent, especially when students enter a university. The shortest time to carry out a blended learning practice is one year. A school in North Carolina s (USA) used the practice for the longest time with its Mathematics and Science Course or nearly 19 years. Almost every school has had initial challenges in using blended learning and showing an improvement in student performance after teaching such courses, but the fundamental reason for encouraging schools to persist in blended learning is that blended learning itself is important to education. In other words, students can adapt to changes in society, in turn improving their learning ability, resulting in improved reading, writing, and computing skills, information processing, problem-solving, communication and cooperation skills, and lifelong learning. These outcomes effectively support the necessity of blended learning.

Inevitable skill requirements in the context of digital technology. Many schools believe that carrying out blended learning will enable students to effectively face the future digital age. Therefore, many schools are willing to spend considerable resources to update and improve an online platform that can provide high-quality learning resources. For instance, the NIS video independently developed by Achievement First Amistad High School (USA) and the eLearning teaching content production and dissemination committed by NCSSM provides students with classroom content that can be accessed repeatedly to help students improve their ability to learn independently in a digital environment. Streetlight Schools in South Africa, namely, Jeppe Park Primary and Sonwabo Primary School, fully use the hardware and software resources originally used for eLearning, viewing digital learning and blended learning as important ways to improve student performance. The rapid development of the digital age is unavoidable, so educators must be proactive to equip students with the survival skills of the future.

\subsection{Problems in blended learning practice}

Certain obstacles may introduce difficulties in practicing blended learning. For example, the traditional and ingrained teaching models need to be disrupted, a proposition that is not acceptable to everyone. When a new learning model emerges that contravenes people past experience, doubt, misunderstanding, and distrust hinder its development. Blended learning is reflected in the continuous updating of educational resources, the updating of teaching strategies, and the updating of 
knowledge transfer methods. The update of the knowledge transfer method means that in blended learning, the way that students acquire knowledge is not as fixed as that in traditional teaching. The transfer does not need to be from teachers to students. Students can acquire knowledge from multiple sources, such as reading from online resources and discussions with mentors or teachers.

The final question for the survey described on the challenges in the development of blended learning practice. The study uses QDA Miner software to carry out qualitative analysis, as shown in Table 5. According to the feedback text, the study divides the analysis types into two categories, namely, is infrastructure (including resources, platforms, space, training, and technology) and ability (including teacher ability, student ability, parent support, and executive ability). The results show that the ability class is the largest obstacle to the effective implementation of blended learning, accounting for $66.6 \%$, and infrastructure construction affects the implementation of mixed learning, accounting for $33.4 \%$ of the total.

Table 5. Qualitative analysis of blended learning disorders

\begin{tabular}{|l|l|c|c|c|c|}
\hline \multicolumn{1}{|c|}{ Category } & \multicolumn{1}{c|}{ Code } & Count & \% Codes & Cases & \% Cases \\
\hline Infrastructure & Resource & 8 & $9.5 \%$ & 1 & $100 \%$ \\
\hline Infrastructure & Platform & 4 & $4.8 \%$ & 1 & $100 \%$ \\
\hline Infrastructure & Space & 5 & $6.0 \%$ & 1 & $100 \%$ \\
\hline Infrastructure & Training & 4 & $4.8 \%$ & 1 & $100 \%$ \\
\hline Infrastructure & Technology & 7 & $8.3 \%$ & 1 & $100 \%$ \\
\hline Ability & Teachers & 18 & $21.4 \%$ & 1 & $100 \%$ \\
\hline Ability & Students & 11 & $13.1 \%$ & 1 & $100 \%$ \\
\hline Ability & Parents & 10 & $11.9 \%$ & 1 & $100 \%$ \\
\hline Ability & Implementing & 17 & $20.2 \%$ & 1 & $100 \%$ \\
\hline
\end{tabular}

A detailed analysis of this problem in four ways is as follows.

How to effectively organize project implementation: During the development of blended learning practice, each school will think about how to implement the project effectively, including judging whether the chosen blended learning model was suitable and whether the quality of the practice scale can be guaranteed. Given that the organization and implementation of the project itself is a complex process, many influencing factors are involved. However, the results of the questionnaire show $37.2 \%$ of schools believe that obtaining the support of the principal or management is essential to the success of blended learning. In addition, $12.6 \%$ of schools believe that the improvement of the quality of blended learning practices is inseparable from parents' participation and understanding.

Inadequate infrastructure: In schools where the blended learning model is implemented, hardware conditions are not the biggest problem facing schools. The limitations of educational software have affected the development of blended learning practices in almost every school. This finding is mainly reflected in the following issues. 1) High-quality online resources are lacking, despite many types of educational software on the market. Schools have to consider the abilities of students, parents, and teachers when choosing online educational software. Thus, the final 
selected software is often interactive and easy to use but low-quality. 2) Data from different education platforms cannot be integrated. Owing to the lack of a comprehensive online learning platform, multiple disciplines will use different learning platforms for practice, and the data between each learning platform cannot be shared. Academic evaluation standards are also inconsistent, causing teachers to spend more time on the manual integration and analysis of data, thereby affecting the efficiency of the entire blended learning practice.

Teachers' lack of practice ability: Given that blended learning remains in the trial stage, insufficient experience for teachers who lead blended learning is normal. Insufficiency of teachers is manifested in three aspects. First, teachers lack understanding of software. For example, at Pathway Christian Centre School (Malaysia), because teachers are not familiar with their software systems, students lean more to the traditional education model rather than the blended learning model. In addition, teachers have insufficient understanding of the blended learning model. For example, at the Escola Projeto School in Brazil, teachers began to use flipped classroom practices in 1998, without knowing which model of the blended learning models they used during development. Only when they systematically learned the flipped classroom model in the blended learning model in 2015, they achieved good results. Finally, teachers lack technical support and monitoring. The lack of necessary technical team support in the process of blended learning development makes teachers unable to solve problems and improve in teaching resource design, platform application, teaching interaction, and data analysis. The teacher's teaching process also lacks the necessary supervision. These influencing factors can be fully amended by targeted training of blended learning skills before the teacher starts the blended learning practice.

Students' insufficient preparation for their skills: In the questionnaire feedback, the words with the highest frequency indicated that students had insufficient prior knowledge, varying degrees of acceptance, and insufficient self-discipline. These problems reflect that when students accept the blended learning model, they also need time to adapt and make a transition. For example, in countries with a relatively short practice time for blended learning, feedback repeatedly indicates that students should be self-disciplined. In countries with a relatively long practice time for blended learning, feedback suggests that students improve self-discipline by cooperating with and supervising each other. Another phenomenon worthy of attention is that students accept blended learning more easily when it is started from a lower grade; by contrast, the transition process of higher-grade students is much slower.

In summary, many reasons hinder the development of blended learning, the most fundamental of which is many theoretical studies on blended learning without much practice. In feedback, the sample size of the participating schools in the United States was very large, and many types of blended learning models were found. The main reason for this phenomenon is that these schools are willing to refine theory into practice. Even if they are not $100 \%$ successful, the school principal is willing to be responsible for all the necessary details. Rick Ogston, principal of Carpe Diem Schools (USA), implemented a disruptive blended learning model in his school, namely, an individual rotation model. Four years later, in Arizona's standardized 
tests, the students in almost all grades of the school ranked first in all subjects [26]. Nathan Gorsch, principal of the Village High School (USA), changed its instructional model from a fully online to a blended learning model. Experience has shown that the school's enrolment has increased significantly, indicating sign that students, families, and the district recognize the value in this new instructional approach [27]. Therefore, blended learning is a long-term practice process. Practicing is necessary to verify and enrich the concept of blended learning.

\section{Conclusion}

To increase the future effectiveness of the blended learning practice and to understand the models and techniques used in the blended learning practice schools, the study used the text mining method to analyse the blended learning practice data collected by Christensen Institute in the past three years. The study suggests that the primary and secondary education stage is suitable for the implementation of the continuity model, providing a certain reference for the selection of practical model, infrastructure preparation (including curriculum, application platform, and teaching resources), and the direction of teacher and student ability training. Accordingly, the development of blended learning in primary and secondary schools faces many opportunities and challenges. Only by examining how it is carried out can educators find ways to solve the obstacles to its development and provide a feasible reference for blended learning practitioners.

\section{References}

[1] Park, Y., Yu, J. H., \& Jo, I. H. (2016). Clustering blended learning courses by online behavior data case study in a Korean higher education institute. Internet and Higher Education, 29: 1-11. https://doi.org/10.1016/j.iheduc.2015.11.001.

[2] Zhu Zhiting, Meng Qi (2003). Blended learning in distance education. Distance Education in China,2003(19): 30-34.

[3] Yu Shengquan, Lu Qiuyu, Chen Shengjian (2005). Blended teaching in network environment - a new teaching mode. University Teaching in China, 2005(10): 50-56.

[4] Feng XiaoYing, Sun Yuwei, Cao Jieting (2019). The role of continuing education in constructing learning cities in the Internet era. Distance Education in China, 2019 (2): 7 18.

[5] García-Ruiz, R., Aguaded, I., \& Bartolomé-Pina, A. (2017). La revolución del blended learning en la educación a distancia. RIED. Revista Iberoamericana de Educación a Distancia, 21(1). https://doi.org/10.5944/ried.21.1.19803.

[6] W. Banyen, C. Viriyavejakul and T. Ratanaolarn (2016).A Blended Learning Model for Learning Achievement Enhancement of Thai Undergraduate Students. International Journal of Emerging Technologies in Learning, Vol. 11(4): 48-55. https://doi.org/10.3991/ ijet.v11i04.5325.

[7] Ding Lei (2016). Physics Teaching in Secondary Vocational School Based on "Internet +". China Educational Technology, 2016 (3): 141-146. 
[8] Xinwen Bi, Xiaodan Shi (2019). On the Effects of Computer-Assisted Teaching on Learning Results Based on Blended Learning Method. International Journal of Emerging Technologies in Learning, Vol. 14(1): 58-70. https://doi.org/10.3991/ijet.v14i01.9458.

[9] Xiangming An, Chengliang Qu (2020). Blending Teaching Mode for Computer Courses in the Background of Emerging Engineering Education. International Journal of Emerging Technologies in Learning, Vol. 15(12): 271-289. https://doi.org/10.3991/ijet.v15.i12.148 67.

[10] Luo Yuanmei, Li Gaoxiang (2019). The Research Hotspot and Evolution of Blended Learning in China. Journal of Guizhou Normal University, 2019(7): 66-73.

[11] Harvi Singh, Chris Reed (2001). A White Paper: Achieving Success with Blended Learning. Centra Software Retrieved, 2001(2): 1-11.

[12] He Kekang (2004). Looking at the new development of educational technology theory from the perspective of blended learning. e- Education Research, 2004(3): 1-22.

[13] Curtis J. Bonk (2006). The handbook of blended learning: global perspectives. John Wiley \& Sons. 2006(12): 218-221.

[14] Zhan Zehui, Li Xiaohua (2009). Blended learning: definition, strategy, current status and development trend. China Audio-visual Education, 2009 (12): 1-5.

[15] Li Fengqing (2016). The theoretical basis and teaching design of blended teaching. Modern Educational Technology, 2016 (9): 18-24.

[16] Wang Rui (2013). Design of Blended Learning Course Based on Claroline Platform. Software Guide (Educational Technology), 2013(7): 30-32.

[17] Chen Yin (2019). Application of Mixed Teaching Mode Based on Superstar Learning. Economic Outlook on the Bohai Rim. 2019(3): 184-185.

[18] Michael B. Horn, Heather Staker (2015). F. Nie, T. Xu, translated. Blended: Using Disruptive Innovation to Improve Schools. China Machine Press, 2015: 1339, 1158.

[19] Denzin, Norman K., and Yvonna S. Lincoln. (2005). Introduction. The discipline and practice of qualitative research. In the Sage handbook of qualitative research, ed. Norman K. Denzin and Yvonna S. Lincoln, 1-32. Thousand Oaks: SAGE Publications. https://doi. org/10.1108/09504120610655394

[20] Braun, V. \& Clarke, V. (2013). Successful qualitative research: A practical guide for beginners. London: Sage.

[21] Leeming, D. (2018). The use of theory in qualitative research. Journal of Human Lactation, 2018, Vol.34 (4), 668-673.

[22] Bryman, A. (2004). Social Research Method (Second edition), NY: Oxford university press, 2004, 266-416.

[23] Xu Yan (2011). A Study of Zhang Wuben Case Though Text Analysis Method of Communication.University of Science and Technology of China. 2011.

[24] CHEN Guo-quan, ZHOU Qi-wei (2018). Modeling Quantitative-style Learning and Qualitative-style Learning: A theoretical study. Journal of Management Sciences in China, 2018, Vol.21(10): 32-46.

[25] "Carpe Diem: Seize the Digital Revolution" Education Nation http://www.education nation.com/casestudies/carnedieml/ (accessed September10, 2013).

[26] The Digital Learning Collaborative (2020). A review of K-12 online, blended, and digital learning. Retrieved February 16, 2020, from https://www.digitallearningcollab.com/ . 


\section{Authors}

Lin Wang is a candidate for doctor's degree in Educational Technology, Faculty of Educational Studies, Universiti Putra Malaysia. She is good at information technology and curriculum integration, blended learning and mobile learning research. In 2019, she was appointed as an associate professor in Educational Science Department, Zhaoqing University, China (2010020009@zqu.edu.cn).

Yanfen Huang is a candidate for doctor's degree in Educational Technology, Faculty of Educational Studies, Universiti Putra Malaysia. She is good at the training of K-12 teachers and skills training for normal university students. Now, she also is a lecturer in Teacher Education Department, Zhaoqing University, China (176480785@qq.com).

Muhd Khaizer Omar is an associate professor at Faculty of Educational Studies, Universiti Putra Malaysia. A Ph.D. Graduate from Oklahoma State University, Stillwater, U.S.A. in Occupational Education Studies. His interests of study are Technical and Vocational Education Training (TVET) and ServiceLearning(khaizer@upm.edu.my).

Article submitted 2020-11-13. Resubmitted 2020-12-15. Final acceptance 2020-12-15. Final version published as submitted by the authors 